\title{
Phase II study of sunitinib in Japanese patients with unresectable or metastatic, well-differentiated pancreatic neuroendocrine tumor
}

\author{
Tetsuhide Ito - Takuji Okusaka - Toshirou Nishida • Kenji Yamao • Hisato Igarashi • \\ Chigusa Morizane • Shunsuke Kondo • Nobumasa Mizuno • Kazuo Hara • \\ Akira Sawaki • Satoshi Hashigaki • Nobuyuki Kimura • Mami Murakami • \\ Emiko Ohki • Richard C. Chao • Masayuki Imamura
}

Received: 4 September 2012 /Accepted: 3 December 2012 /Published online: 27 December 2012

(C) The Author(s) 2012. This article is published with open access at Springerlink.com

Summary Background. Pancreatic neuroendocrine tumors (NETs) are rare but are frequently diagnosed at advanced stages and require systemic therapy. Patients and methods. This multicenter, open-label, phase II study evaluated sunitinib in Japanese patients with well-differentiated pancreatic NET. Patients received sunitinib $37.5 \mathrm{mg}$ /day on a continuous daily dosing (CDD) schedule. The primary endpoint was clinical benefit rate (CBR; percentage of complete responses [CRs] plus partial responses [PRs] plus stable disease [SD] $\geq 24$ weeks). Secondary endpoints included objective response rate (ORR), tumor shrinkage, progression-free survival (PFS) probability, safety, pharmacokinetics, and

Akira Sawaki is a Previous Aichi Cancer Center Hospital employee.

Mami Murakami is a Previous Pfizer Japan Inc. employee.

Electronic supplementary material The online version of this article (doi:10.1007/s10637-012-9910-y) contains supplementary material, which is available to authorized users.

T. Ito $(\bowtie) \cdot H$. Igarashi

Department of Medicine and Bioregulatory Science, Graduate

School of Medical Science, Kyushu University,

3-1-1 Maidashi Higashi-ku,

Fukuoka, Japan

e-mail: itopapa@intmed3.med.kyushu-u.ac.jp

T. Okusaka $\cdot$ C. Morizane $\cdot$ S. Kondo

Hepatobiliary and Pancreatic Oncology Division, National Cancer

Center Hospital, Tokyo, Japan

T. Nishida

Department of Surgery, Osaka Police Hospital, Osaka, Japan

K. Yamao $\cdot$ N. Mizuno $\cdot$ K. Hara $\cdot$ A. Sawaki

Department of Gastroenterology, Aichi Cancer Center Hospital,

Nagoya, Japan biomarkers. Results. Twelve patients received treatment. The CBR was $75 \%$ (95\% confidence interval [CI], 43-94) and included 6 patients with a PR and 3 with SD. The ORR was $50 \%$ (95\% CI, 21-79). PFS probability was $91 \%$ (95\% CI, 54-99) at 6 months and $71 \%$ (95\% CI, 34-90) at 12 months. Commonly reported treatment-emergent (all-causality), anygrade adverse events included diarrhea $(n=10)$, hand-foot syndrome and hypertension (both $n=8$ ), fatigue and headache (both $n=7)$, and neutropenia $(n=6)$. No deaths on study were reported; one death due to disease progression occurred $>28$ days after end of treatment. Sunitinib on a CDD schedule resulted in sustained drug concentrations without accumulation across cycles. Tumor

\author{
S. Hashigaki $\cdot$ N. Kimura $\cdot$ M. Murakami $\cdot$ E. Ohki \\ Pfizer Japan Inc., Tokyo, Japan \\ R. C. Chao \\ Pfizer Oncology, La Jolla, CA, USA \\ M. Imamura \\ Kansai Electric Power Company Hospital, Osaka, Japan
}

Present Address:

A. Sawaki

Nagoya Daini Red Cross Hospital, Nagoya, Japan

Present Address:

M. Murakami

Drug Delivery and Formulation Group, Medicinal Chemistry

Platform, Ontario Institute for Cancer Research, Toronto, ON,

Canada 
responses in all 12 patients did not appear to correlate with decreases in chromogranin A levels. Conclusions. Sunitinib $37.5 \mathrm{mg}$ /day on a CDD schedule demonstrated antitumor activity in Japanese patients with unresectable, well-differentiated pancreatic NET. Commonly reported adverse events were consistent with the known safety profile of sunitinib.

Keywords Efficacy · Japanese · Pancreatic neuroendocrine tumor $\cdot$ Pharmacokinetics $\cdot$ Phase II $\cdot$ Sunitinib

\section{Introduction}

Pancreatic neuroendocrine tumors (NETs) are rare malignancies with a prevalence of 2.23 per 100,000 population in Japan [1]. The incidence rate of pancreatic NET per year in Japan (1.01 per 100,000 population) appears higher than in Western countries $(0.32 / 100,000$ in the overall US population and 0.25 in Asian Americans [2]). Surgery, if feasible, is the optimal treatment approach [3]. However, the majority of patients present with unresectable disease. When the current study was initiated, treatment options available for symptomatic patients with unresectable disease included somatostatin analogs (e.g. octreotide, alone or in combination with interferon-alpha) and the alkylating agent streptozocin (alone or in combination with doxorubicin), both of which have limited efficacy in patients with advanced disease [4-6]. Subsequently, targeted anticancer agents have been shown to improve progression-free survival (PFS) compared with placebo in phase III studies that included primarily Caucasian patients with advanced pancreatic NET [7-9].

Vascular endothelial growth factor (VEGF) and plateletderived growth factor (PDGF) are key drivers of angiogenesis in pancreatic NETs $[10,11]$. Sunitinib malate (SUTENT $\left.{ }^{\circledR}\right)$, an oral multitargeted inhibitor of numerous receptor tyrosine kinases including VEGF receptors and PDGF receptors [12-14], has been shown to delay tumor growth in a RIP1Tag2 transgenic mouse model of pancreatic islet-cell tumors $[15,16]$. In a phase II trial, sunitinib demonstrated antitumor activity in patients with pancreatic NET [17], and in a subsequent phase III trial, oral sunitinib $37.5 \mathrm{mg}$ /day on a continuous daily dosing (CDD) schedule prolonged median PFS relative to placebo in Caucasian and Asian patients with locally advanced and/or metastatic, well-differentiated pancreatic NET [7]. Sunitinib was also associated with a greater objective tumor response rate than placebo. In an updated analysis, median overall survival (OS) favored sunitinib (hazard ratio [HR] 0.71, $95 \%$ confidence interval [CI]: 0.47-1.09; $P=0.11$ ), despite crossover to sunitinib for most of the patients randomized to placebo, although statistical significance was not reached [18]. On the basis of these findings, sunitinib has been approved multinationally for the treatment of patients with unresectable or metastatic, well-differentiated pancreatic NET with disease progression.

We carried out a phase II, open-label, multicenter trial (NCT01121562) to evaluate the clinical benefit rate (CBR) of sunitinib in Japanese patients with pancreatic NET. The sunitinib dose investigated was $37.5 \mathrm{mg}$ /day on the CDD schedule, which was the same regimen used in a Western phase III study [7]. Secondary objectives were to assess objective response rate (ORR) and PFS, to evaluate safety and tolerability, and to determine the pharmacokinetic (PK) profile of sunitinib in this patient population.

\section{Patients and methods}

\section{Study population}

Japanese patients $\geq 20$ years old with histologically or cytologically proven, well-differentiated pancreatic NET (according to the World Health Organization 2004 classification [19]) and progressive unresectable advanced or metastatic disease were eligible to participate. Inclusion criteria comprised documented evidence of disease progression within 12 months of study start (by computed tomography [CT] or magnetic resonance imaging [MRI]), and disease not amenable to surgery, radiation, or combined modality therapy with curative intent. At least one measurable target lesion according to Response Evaluation Criteria in Solid Tumors (RECIST) version 1.0 [20] was required, along with adequate organ function, an Eastern Cooperative Oncology Group performance status (ECOG PS) of 0 or 1 , and a life expectancy of at least 3 months. Patients were excluded if they had poorly differentiated tumors, prior treatment with any tyrosine kinase or antiVEGF angiogenic inhibitors, brain metastases, cardiovascular disease $\leq 12$ months prior to study start, uncontrolled hypertension, an uncontrolled thyroid abnormality, ongoing cardiac dysrhythmias with medical intervention or a prolonged QT interval corrected for heart rate (QTc), symptomatic brain metastases, or a left ventricular ejection fraction of $\leq 50 \%$.

Study design and treatment

In this multicenter, open-label, phase II study, all patients received oral sunitinib37.5 $\mathrm{mg} /$ day on a CDD schedule, and each treatment cycle lasted 28 days. Patients were monitored for toxicity, and dose reductions to $25 \mathrm{mg}$ /day were permitted based on individual tolerability. The sunitinib dose could also be increased to $50 \mathrm{mg}$ /day (if no response was observed in the first 8 weeks and if individual tolerability permitted). The primary endpoint was $\mathrm{CBR}$, defined as the proportion of patients with a confirmed complete response (CR) or partial response (PR) or stable disease (SD) for $\geq 24$ weeks. CBR was selected as the primary endpoint because maintaining 
prolonged SD over about half of a year (24 weeks) was deemed beneficial and clinically meaningful for patients with pancreatic NET, based on the median PFS of 5.5 months reported for placebo treatment in a previous global, pivotal, phase III study [7]. Secondary efficacy endpoints included ORR, defined as the proportion of patients with a confirmed $\mathrm{CR}$ or PR; tumor shrinkage, defined as the percentage change from baseline in the sum of the longest diameter of target lesions; PFS; safety; and PK.

The study was conducted in accordance with the International Conference on Harmonization Good Clinical Practice guidelines, the Declaration of Helsinki, and applicable local regulatory requirements and laws. Approval from the institutional review board or independent ethics committee of each participating center was required, and written informed consent was obtained from all patients before screening.

\section{Study assessments}

Investigator-assessed tumor imaging by $\mathrm{CT}$, spiral CT, or MRI was performed at screening and weeks 5 and 9 , and then at 8week intervals during the study. Additional scans were performed when disease progression was suspected or to confirm a CR or PR based on RECIST. Safety was assessed at regular intervals by physical examination and analysis of adverse events (AEs), laboratory abnormalities (hematology and blood chemistry), vital signs, 12-lead electrocardiograms (ECGs), and ECOG PS. AEs were graded using National Cancer Institute Common Terminology Criteria for Adverse Events, version 4.0. QTc intervals were determined using 12lead ECGs in triplicate at baseline, on day 1 of cycles 2 and 3, every 8 weeks thereafter, and as clinically indicated.

Blood samples were collected before dosing on day $15( \pm 1)$ of cycle 1 and on day 1 of cycles $2-4$ to evaluate trough concentrations $\left(\mathrm{C}_{\text {trough }}\right)$ of sunitinib and its active metabolite SU12662 using a validated high- performance liquid chromatography-tandem mass spectrometry method (Bioanalytical Systems Inc., West Lafayette, Indiana, USA). An exploratory analysis investigated potential differences in steady-state $\mathrm{C}_{\text {trough }}$ values of sunitinib, SU12662, and total drug (sunitinib plus SU12662) in Japanese versus non-Japanese patient populations and in patients with different tumor types. $\mathrm{C}_{\text {trough }}$ from this Japanese study, a Western pancreatic NET trial [15], and from studies of Japanese patients with GIST or RCC [21, 22] were dose-corrected to $37.5 \mathrm{mg}$ and compared.

Blood samples were obtained at screening, week 5, and week 9 , and then every 8 weeks to assess chromogranin A (CgA) levels (all patients) and hormone levels (patients with functional tumors only). Patients were required to fast for $\geq 10 \mathrm{~h}$ prior to each scheduled visit. In an exploratory analysis of $\mathrm{CgA}$ levels, a biochemical response was defined as a $\geq 50 \%$ decrease in $\mathrm{CgA}$ levels among patients with elevated $\mathrm{CgA}$ levels at baseline.
Statistical methods

As pancreatic NETs are rare, a target sample size of at least 10 patients was determined based on feasibility of study conduct rather than statistical requirements. All enrolled patients who received at least one dose of study treatment were included in the efficacy and safety analyses.

Descriptive statistics were used to summarize patient characteristics, treatment administration/compliance, safety parameters, and PK variables. For the analysis of the primary endpoint, the CBR and its exact $95 \%$ CI were calculated. For the analysis of the secondary endpoints, the ORR and its exact $95 \% \mathrm{CI}$, and the percentage change from baseline in the sum of the longest diameter of target lesions were calculated. Time-to-event endpoints (PFS and OS) were summarized using Kaplan-Meier methods.

\section{Results}

Patients and treatment

Between July and December 2010, 12 patients (8 male, 4 female) were enrolled in the study at four centers in Japan. All patients received treatment and were analyzed for efficacy and safety. At data cut-off (March 2012), treatment was ongoing in 5 patients with a PR $(n=4)$ or $\mathrm{SD}(n=1)$, and 7 patients had withdrawn from the trial. Study withdrawals were due to tumor progression or recurrence $(n=3)$, withdrawal of consent $(n=1)$, treatment interruption $>4$ weeks due to a serious adverse event (SAE; grade 4 enterocolitis; $n=1$ ), and SAEs (grade 4 convulsion plus grade 4 loss of consciousness; $n=1$ ). Demographic and baseline disease characteristics are presented in Table 1. All of the patients had well-differentiated pancreatic NETs, of which 10 were classified as nonfunctional and 2 as functional (both gastrinomas). Six patients had received prior octreotide treatment and continued octreotide therapy during the study.

The median relative sunitinib dose intensity was $51 \%$ (range, 26-94); the median number of treatment cycles started was 16 (range, 3-21; Table 2). The sunitinib dose was interrupted in 11 patients and reduced in 8 patients. The most frequently reported cause of dosing interruptions or reductions was AEs.

\section{Efficacy}

Based on investigator assessments, 6 of the 12 patients experienced a PR, and none had a CR (Fig. 1). SD $\geq 24$ weeks was observed in 3 patients, and the CBR was $75 \%$ (95\% CI, 43-94). In total, 5/6 patients with prior or concurrent octreotide treatment and $4 / 6$ patients who did not receive octreotide met the criteria for experiencing clinical 
Table 1 Patient characteristics at baseline

\begin{tabular}{|c|c|}
\hline Patient characteristic & Sunitinib $(N=12)$ \\
\hline \multicolumn{2}{|l|}{ Age, years } \\
\hline Median & 54 \\
\hline Range & $34-79$ \\
\hline \multicolumn{2}{|l|}{ Sex, $n(\%)$} \\
\hline Male & $8(67)$ \\
\hline Female & $4(33)$ \\
\hline \multicolumn{2}{|c|}{ ECOG performance status, $n(\%)$} \\
\hline 0 & $11(92)$ \\
\hline 1 & $1(8)$ \\
\hline \multicolumn{2}{|c|}{ Time since diagnosis, years } \\
\hline Median & 3 \\
\hline Range & $0.2-9.0$ \\
\hline \multicolumn{2}{|c|}{ Tumor functionality, $n(\%)$} \\
\hline Nonfunctioning & $10(83)$ \\
\hline Functioning & $2(17)$ \\
\hline Gastrinoma & $2(17)$ \\
\hline \multicolumn{2}{|c|}{ Number of involved disease sites per patient, $n(\%)$} \\
\hline 1 site & $4(33)$ \\
\hline 2 sites & $5(42)$ \\
\hline 3 sites & $2(17)$ \\
\hline 4 sites & $1(8)$ \\
\hline \multicolumn{2}{|c|}{ Presence of distant metastases, $n(\%)$} \\
\hline Any, including hepatic & $12(100)$ \\
\hline Extrahepatic & $3(25)$ \\
\hline \multicolumn{2}{|c|}{ Involved disease sites, $n(\%)$} \\
\hline Liver & $12(100)$ \\
\hline Lymph node & $4(33)$ \\
\hline Pancreas & $4(33)$ \\
\hline Lung & $2(17)$ \\
\hline Bone & $1(8)$ \\
\hline Peritoneum & $1(8)$ \\
\hline \multicolumn{2}{|l|}{ Prior surgery, $n(\%)$} \\
\hline Yes & $9(75)$ \\
\hline No & $3(25)$ \\
\hline \multicolumn{2}{|c|}{ Prior radiation therapy, $n(\%)$} \\
\hline Yes & $1(8)$ \\
\hline No & $11(92)$ \\
\hline \multicolumn{2}{|c|}{ Number of prior systemic chemotherapy regimens, $n(\%)$} \\
\hline 0 & $6(50)$ \\
\hline 1 & $4(33)$ \\
\hline 2 & 0 \\
\hline$\geq 3$ & $2(17)$ \\
\hline
\end{tabular}

ECOG Eastern cooperative oncology group

benefit. The overall ORR was $50 \%(95 \%$ CI, 21-79; Fig. 1). One patient showed a $100 \%$ decrease in target lesion size. One PR occurred in a patient with gastrinoma and was accompanied by a $93 \%$ decrease in plasma gastrin
Table 2 Sunitinib treatment

Sunitinib $(N=12)$

Treatment cycles started, median (range)

$16(3-21)$

Months on treatment, median (range)

$10(0.7-18)$

Months on study, median (range)

$14(0.7-19)$

No. of patients with $\geq 1$ dosing interruption, $n(\%) \quad 11$ (92)

No. of patients with $\geq 1$ dose reduction, $n(\%) \quad 8$ (67)

Relative dose intensity, median (range), \% 51 (26-94)

levels (Patient D; Data Supplement Table S1; see also below). In 11/12 patients, some degree of tumor shrinkage was observed by the first assessment 1 month after initiation of sunitinib treatment (Fig. 2). At the time of data cut-off, ongoing patients had been observed for at least 16.1 months, and the median duration of treatment with sunitinib was 9.8 months (range, 0.7-18.1). Although 4/12 patients had discontinued treatment with sunitinib due to reasons other than progressive disease (PD), median PFS had not yet been reached. Six-month and 12-month PFS probabilities were $91 \%$ (95\% CI, 54-99) and $71 \%$ (95\% CI, 34-90), respectively. Median OS had not yet been reached. One death occurred (due to progression of primary disease) during survival follow-up, more than 28 days after the end of treatment.

\section{Safety}

As of March 2012, the most common treatment-emergent (all-causality) AEs of any grade were diarrhea $(n=10$; $83 \%$ ), hand-foot syndrome and hypertension (both $n=8$; $67 \%$ ); fatigue and headache (both $n=7 ; 58 \%$ ), and neutropenia $(n=6 ; 50 \%$; Table 3). Grade 3 AEs reported in at least 2 patients were neutropenia $(n=6 ; 50 \%)$ and leukopenia $(n=2 ; 17 \%)$. Four patients (33\%) experienced grade 4 AEs, all of which were judged to be related to treatment (herpes encephalitis, convulsion, and loss of consciousness $[n=1]$, increased lipase $[n=2]$, and enterocolitis [ $n=1])$. No deaths related to sunitinib treatment were reported on study or within 28 days of the end of treatment. One death due to disease progression occurred $>28$ days after end of treatment.

Three patients $(25 \%)$ experienced SAEs, all of which resolved. In two cases, the SAEs were assessed as treatmentrelated. One patient (patient H; Fig. 2) had a grade 4 convulsion and grade 4 loss of consciousness that were reported to be likely due to herpes encephalitis. These SAEs resulted in a sunitinib dose interruption exceeding 4 weeks that led to study discontinuation, as specified in the protocol. Another patient (patient K; Fig. 2) experienced an SAE of grade 4 enterocolitis and temporarily discontinued therapy due to this SAE. 
Fig. 1 Maximum percentage reduction from baseline in target lesion size by patient $(N=$ 12). Although one patient had a maximum percentage change in target tumor size from baseline of $-100 \%$, non-target lesions remained and therefore this was not classified as a complete response. Asterisk stable disease of $\geq 24$ weeks in duration; RECIST Response Evaluation Criteria in Solid Tumors

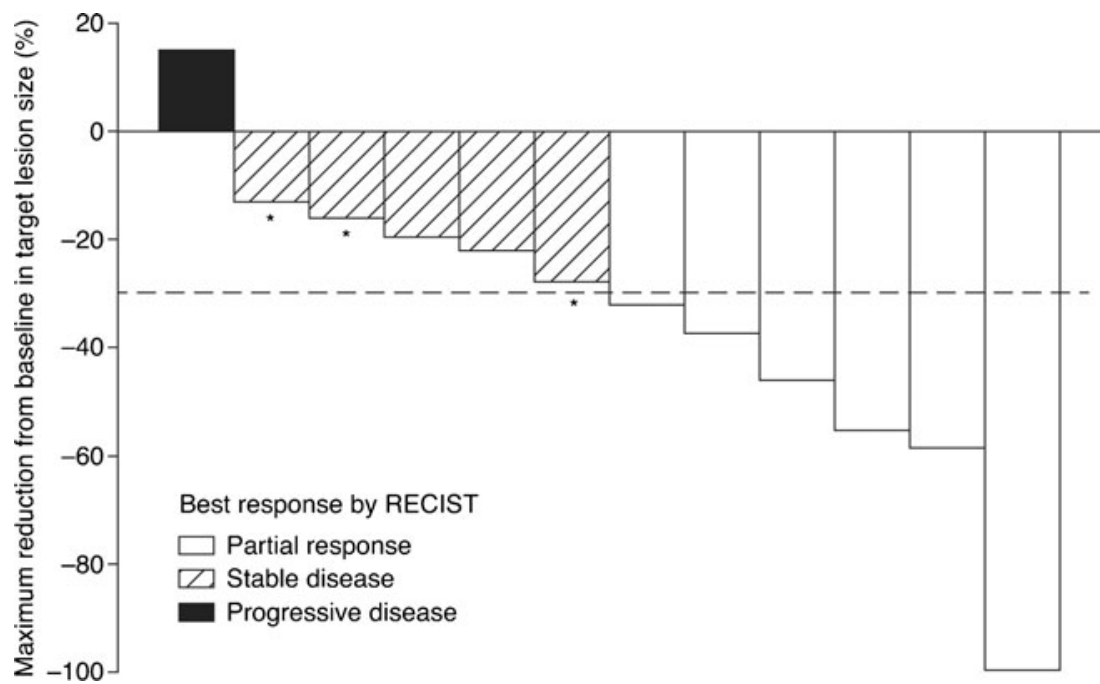

Pharmacokinetics

Steady-state concentrations of sunitinib, SU12662, and total drug (sunitinib plus SU12662) were reached by day 15 of cycle 1 . Subsequent sampling on day 1 of cycles $2-4$ showed the concentrations to be sustained following CDD with sunitinib without disproportionate accumulation across cycles (data not shown). Mean dose-corrected (reference dose: $37.5 \mathrm{mg}$ ) $\mathrm{C}_{\text {trough }}$ values were within the ranges of $41.7-$ $53.9 \mathrm{ng} / \mathrm{mL}$ for sunitinib, 19.6-25.7 $\mathrm{ng} / \mathrm{mL}$ for SU12662, and $62.9-77.5 \mathrm{ng} / \mathrm{mL}$ for total drug.

We explored potential differences in steady-state $\mathrm{C}_{\text {trough }}$ values of sunitinib and SU12662 in Japanese versus nonJapanese patient populations and in patients with different tumor types. Dose-corrected steady-state $\mathrm{C}_{\text {trough }}$ levels from this Japanese study were compared with findings from a Western pancreatic NET population [17], and from studies of Japanese patients with gastrointestinal stromal tumor (GIST) or renal cell carcinoma (RCC) [21, 22]. Steadystate $\mathrm{C}_{\text {trough }}$ levels of sunitinib, SU12662, or total drug were not significantly different between Japanese and primarily Western patients with pancreatic NET, or between patients with pancreatic NET, GIST, and RCC tumor types (Fig. 3).

\section{Biomarkers}

\section{Chromogranin A}

Plasma CgA levels were measured in all 12 patients (Fig. 2). At baseline, the median $\mathrm{CgA}$ concentration was $9 \mathrm{pmol} / \mathrm{mL}$ (range, 3-86 pmol/mL). Six patients had above-median $\mathrm{CgA}$ levels at baseline, 3 of whom had a maximum percentage decrease in $\mathrm{CgA}$ concentrations of at least $-50 \%$. Among these 3 patients, 2 had a PR and 1 had a best overall response of $\mathrm{SD}$. In the patient with $\mathrm{SD}$, the maximum percentage change in tumor size from baseline was $-28 \%$. Among the 6 patients with below-median CgA levels, 3 experienced a PR and 3 had a best overall response of SD. Tumor responses in all 12 patients did not appear to correlate with the maximum percentage decrease in CgA levels.

\section{Gastrin}

Plasma gastrin levels were assessed in the 2 patients with gastrinomas: a 40-year-old female (patient D) and a 34-yearold male (patient L; Data Supplement Table S1). In addition, the relationship between hormonal levels, tumor size, and objective tumor response (based on investigator assessment) was examined in an exploratory analysis. In the male patient, neither gastrin levels nor tumor size decreased after treatment with sunitinib. The best objective response was $\mathrm{PD}$, and the patient discontinued the study at day 79 due to lack of efficacy. In the female patient with gastrinoma, decreases in both gastrin levels $(-85 \%$ to $-93 \%)$ and tumor size $(-31 \%$ to $-45 \%)$ were observed during treatment. This patient had a PR on cycle 2 day 1 that was maintained through cycle 7 day 1 .

\section{Discussion}

This is the first report of sunitinib safety, PK profiles, PFS, and antitumor activity in Japanese patients with unresectable, advanced/metastatic well-differentiated pancreatic NET. While the data are limited by the small sample size, antitumor activity was observed in this population, with a CBR of $75 \%$ and an ORR of $50 \%$. The ORR was encouraging and higher than the $9 \%$ ORR reported for sunitinib in a randomized, phase III trial in a predominantly non-Asian population [7]. In the present study, 11 patients had 


\begin{tabular}{|c|c|c|c|c|c|c|c|c|c|}
\hline \multirow[t]{2}{*}{ Patient } & \multirow{2}{*}{$\begin{array}{l}\text { Age, } \\
\text { sex }\end{array}$} & \multirow{2}{*}{$\begin{array}{l}\text { Tumor } \\
\text { functionality }\end{array}$} & \multirow[t]{2}{*}{ Prior treatment } & \multirow{2}{*}{$\begin{array}{l}\text { Maximum } \\
\text { change in target } \\
\text { lesion size }(\%)^{\mathrm{a}}\end{array}$} & \multirow{2}{*}{$\begin{array}{l}\text { Best } \\
\text { overall } \\
\text { response }\end{array}$} & \multirow{2}{*}{$\begin{array}{l}\text { PFS } \\
\text { (months) }\end{array}$} & \multirow{2}{*}{$\begin{array}{l}\text { Reason for } \\
\text { discontinuation }\end{array}$} & \multicolumn{2}{|c|}{ Chromogranin A } \\
\hline & & & & & & & & $\begin{array}{l}\text { Baseline } \\
\text { concentration } \\
\text { (pmol/mL) }\end{array}$ & $\begin{array}{l}\text { Maximum change } \\
\text { from baseline } \\
(\%)^{\mathrm{a}}\end{array}$ \\
\hline A & $62, \mathrm{~F}$ & Non-functioning & $\begin{array}{l}\text { Gemcitabine, } \\
\text { somatostatin analogs }\end{array}$ & -100 & PR & 11.1 & PD & 4 & 5 \\
\hline B & $44, \mathrm{M}$ & Non-functioning & Epirubicin, mitomycin-C & -59 & PR & $18.6^{\circ}$ & None - ongoing & 3 & 62 \\
\hline c & $64, \mathrm{~F}$ & Non-functioning & $\begin{array}{l}\text { Epirubicin, somatostatin } \\
\text { analogs }\end{array}$ & -56 & PR & $16.6^{b}$ & None- ongoing & 13 & -53 \\
\hline D & $40, F$ & $\begin{array}{l}\text { Functioning } \\
\text { (gastrinoma) }\end{array}$ & Somatostatin analogs & -46 & PR & $15.0^{\circ}$ & None - ongoing & 86 & -89 \\
\hline $\mathrm{E}$ & $64, \mathrm{M}$ & Non-functioning & None & -38 & PR & 14.8 & PD & 4 & 47 \\
\hline$F$ & $51, M$ & Non-functioning & $\begin{array}{l}\text { Cisplatin, etoposide, } \\
\text { somatostatin analogs }\end{array}$ & -33 & PR & $14.8^{\mathrm{b}}$ & None - ongoing & 10 & -5 \\
\hline G & $46, M$ & Non-functioning & $\begin{array}{l}\text { Fluorouracil, cisplatin, } \\
\text { gemcitabine, } \\
\text { streptozocin, tegafur- } \\
\text { uracil, somatostatin } \\
\text { analogs }\end{array}$ & -28 & SD & 9.3 & PD & 18 & -73 \\
\hline $\mathrm{H}$ & $57, \mathrm{M}$ & Non-functioning & Somatostatin analogs & -22 & SD & $2.4^{\circ}$ & $\begin{array}{l}\text { Treatment interruption } \\
>4 \text { consecutive } \\
\text { weeks due to lack } \\
\text { of tolerance (serious } \\
\text { adverse events of } \\
\text { convulsion and loss } \\
\text { of consciousness) }\end{array}$ & 7 & -37 \\
\hline 1 & $64, \mathrm{~F}$ & Non-functioning & None & -20 & SD & $2.1^{\mathrm{b}}$ & $\begin{array}{l}\text { Withdrawal of } \\
\text { informed consent }\end{array}$ & 16 & -1 \\
\hline $\mathrm{J}$ & $44, \mathrm{M}$ & Non-functioning & $\begin{array}{l}\text { Epirubicin, cisplatin, } \\
\text { cancer vaccinations, } \\
\text { cyclophosphamide }\end{array}$ & -16 & SD & $18.5^{\circ}$ & None - ongoing & 6 & -19 \\
\hline K & $79, M$ & Non-functioning & None & -13 & SD & $13.0^{\mathrm{b}}$ & $\begin{array}{l}\text { Serious adverse event } \\
\text { (grade } 4 \text { enterocolitis) }\end{array}$ & 8 & -29 \\
\hline L & $34, \mathrm{M}$ & $\begin{array}{l}\text { Functioning } \\
\text { (gastrinoma) }\end{array}$ & None & 15 & PD & 2.0 & PD & 21 & 300 \\
\hline
\end{tabular}

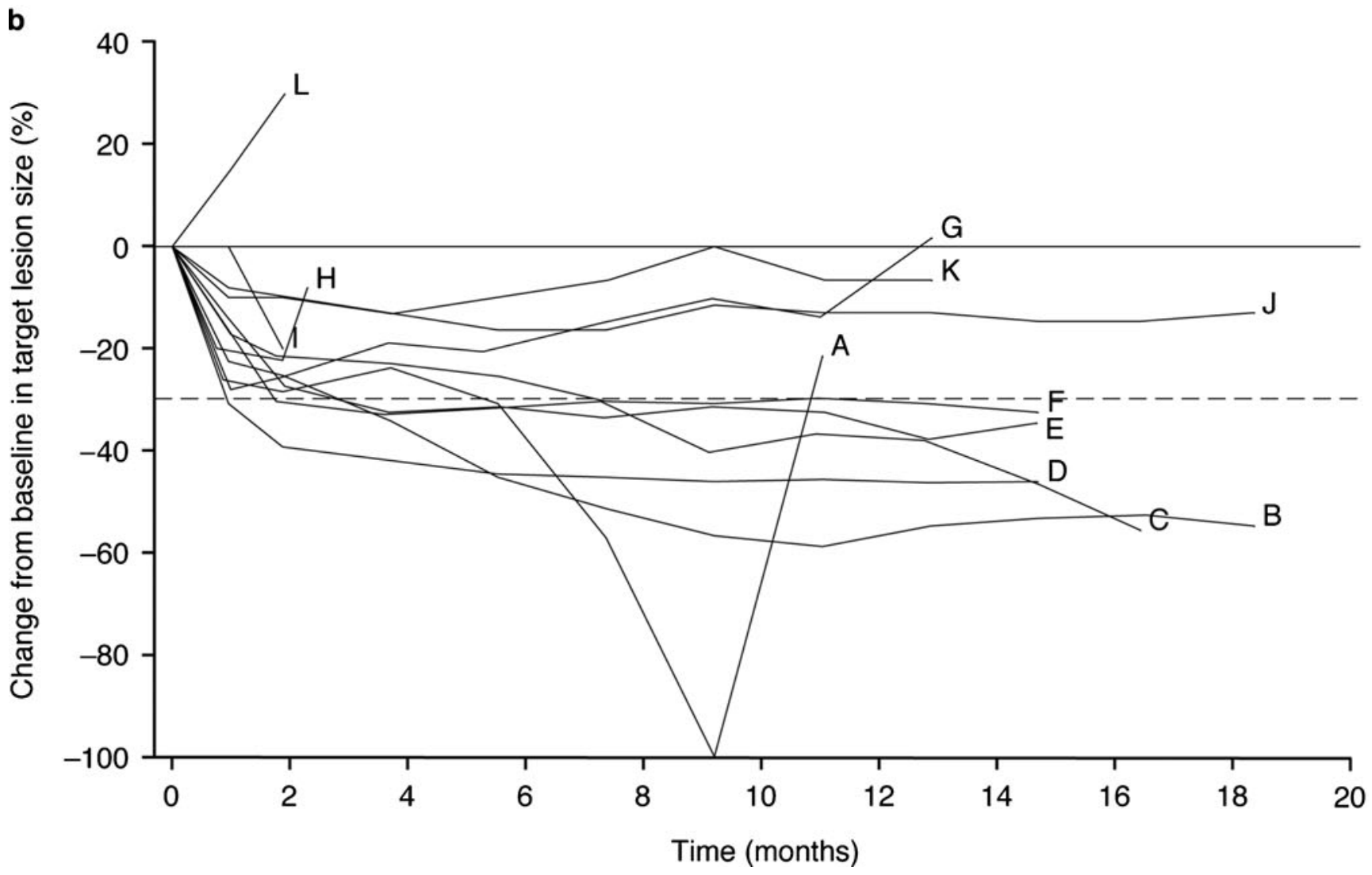


Fig. 2 Individual patient profiles and response to treatment $(N=12)$. a Summary of patient profiles and changes in tumor-size and chromogranin A levels. b Percentage change from baseline in target lesion size over time in individual patients. ${ }^{a}$ Maximum $\%$ change $=[$ (minimum value after dosing - baseline)/baseline] x $100 ;{ }^{\mathrm{b}}$ Based on censored data; $F$ female; $M$ male; $P D$ progressive disease; $P F S$ progression-free survival; $P R$ partial response; $S D$ stable disease

decreases in target lesion measurements and achieved a best response of a PR or SD. Analysis of the percentage change in target lesion size over time showed a trend in tumor shrinkage from the first assessment 1 month after initiation of treatment with sunitinib. As of March 2012, ongoing patients had been observed for at least 16.1 months, and median PFS had not been reached. The probability of being alive and progression-free at 6 months was $91 \%(95 \% \mathrm{CI}$, 54-99) and at 12 months was $71 \%(95 \%$ CI, 34-90). In the randomized sunitinib phase III trial, median PFS was 11.4 months [7]. These data suggest that PFS in Japanese patients receiving sunitinib in our study may be equivalent to or greater than that observed in the randomized phase III trial.

The potential effect of octreotide therapy was difficult to evaluate in this study due to the small sample size. The CBR was similar among patients with $(n=5 / 6)$ or without $(n=4 / 6)$ octreotide treatment. In an exploratory subpopulation analysis reported in the randomized sunitinib phase III study, the efficacy of sunitinib appeared similar in patients who did and did not receive somatostatin analogues (PFS hazard ratios of 0.43 and 0.41 , respectively), suggesting that the efficacy of sunitinib was not affected by somatostatin analogue treatment [7].

AEs reported during sunitinib treatment were manageable with palliative care measures, such as dosing interruption. The AEs observed in this study were similar to those reported in a phase III study in primarily Western patients with pancreatic NET [7], and frequently observed AEs were comparable to those reported in patients with GIST or RCC $[21,22]$.

In the current study, the median number of treatment cycles started was 16. All patients had grade 3/4 AEs and at least one sunitinib dosing interruption. However, the therapeutic effect of sunitinib did not appear to be reduced by temporary dosing interruptions due to AEs. Neutropenia, the most common grade $3 / 4 \mathrm{AE}$, was also the most frequently reported grade $3 / 4$ toxicity in the predominantly Western sunitinib phase III pancreatic NET study [7], although the frequency of this event was markedly higher in our study with Japanese patients ( $42 \%$ vs. $12 \%$ ). Increased rates of grade $3 / 4$ neutropenia have also been observed in sunitinibtreated Japanese patients with GIST (37\% vs. $10 \%$ ) or RCC (53\% vs. $18 \%$ ), compared with predominantly Western populations [21-24]. The frequency of grade 3/4 thrombocytopenia similarly appeared to be higher in sunitinib-treated Japanese vs. Western patients (GIST: $20 \%$ vs. $4 \%$; RCC: $55 \%$ vs. $9 \%$; pancreatic NET:
Table 3 Treatment-emergent (all-causality) adverse events (AEs) reported in $\geq 25 \%$ of patients, according to the National Cancer Institute Common Terminology Criteria for Adverse Events version 4.0

${ }^{\mathrm{a}}$ Grade 4 AEs were observed in 4 patients: convulsion, loss of consciousness, and herpes encephalitis $(n=1)$, increased lipase $(n=2)$, and enterocolitis $(n=1)$; no grade 5 AEs were reported

${ }^{\mathrm{b}}$ Patients were counted once, with only the highest grade $\mathrm{AE}$ listed

\begin{tabular}{|c|c|c|c|c|}
\hline \multirow[b]{2}{*}{$\begin{array}{l}\mathrm{AE} \\
\text { Any } \mathrm{AE}^{\mathrm{b}}\end{array}$} & \multicolumn{4}{|c|}{ Maximum grade $(\mathrm{G}), n(\%)$} \\
\hline & $\begin{array}{l}\text { G1 } \\
0\end{array}$ & $\begin{array}{l}\mathrm{G} 2 \\
0\end{array}$ & $\begin{array}{l}\text { G3 } \\
8\end{array}$ & $\begin{array}{l}\text { Total }^{\mathrm{a}} \\
12(100)\end{array}$ \\
\hline Diarrhea & $4(33)$ & $5(42)$ & $1(8)$ & $10(83)$ \\
\hline Hand-foot syndrome & $1(8)$ & $7(58)$ & 0 & $8(67)$ \\
\hline Hypertension & $1(8)$ & $7(58)$ & 0 & $8(67)$ \\
\hline Fatigue & $1(8)$ & $6(50)$ & 0 & $7(58)$ \\
\hline Headache & $4(33)$ & $3(25)$ & 0 & $7(58)$ \\
\hline Neutropenia & 0 & 0 & $6(50)$ & $6(50)$ \\
\hline Dysgeusia & $5(42)$ & 0 & 0 & $5(42)$ \\
\hline Nasopharyngitis & $4(33)$ & $1(8)$ & 0 & $5(42)$ \\
\hline Nausea & $4(33)$ & $1(8)$ & 0 & $5(42)$ \\
\hline Pyrexia & $2(17)$ & $2(17)$ & $1(8)$ & $5(42)$ \\
\hline Vomiting & $5(42)$ & 0 & 0 & $5(42)$ \\
\hline Decreased appetite & $4(33)$ & 0 & 0 & $4(33)$ \\
\hline Edema & $3(25)$ & $1(8)$ & 0 & $4(33)$ \\
\hline Hypothyroidism & 0 & $4(33)$ & 0 & $4(33)$ \\
\hline Leukopenia & 0 & $1(8)$ & $2(17)$ & $3(25)$ \\
\hline Mucosal inflammation & $2(17)$ & $1(8)$ & 0 & $3(25)$ \\
\hline Muscle spasms & $3(25)$ & 0 & 0 & $3(25)$ \\
\hline Prolonged electrocardiogram QT & $1(8)$ & $1(8)$ & $1(8)$ & $3(25)$ \\
\hline Thrombocytopenia & $1(8)$ & $1(8)$ & $1(8)$ & $3(25)$ \\
\hline
\end{tabular}




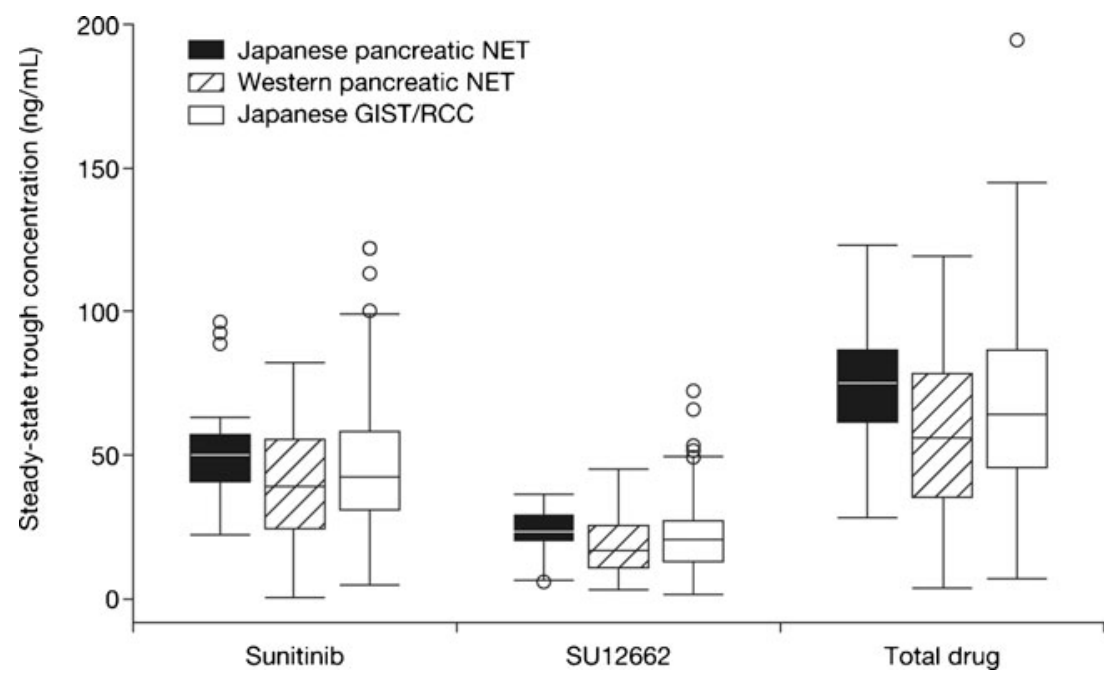

Fig. 3 Trough concentrations of sunitinib, active metabolite SU12662, and total drug (sunitinib plus SU12662) in Japanese patients with pancreatic neuroendocrine tumor (NET; $n=11$; present study) or gastrointestinal stromal tumor (GIST; $n=30$ ) [21] and renal cell carcinoma (RCC; $n=38$; pooled data) [25], and in predominantly Western patients with pancreatic NET; $n=57$ [17]. The sunitinib dose in each study was dose-corrected to $37.5 \mathrm{mg}$. The upper and lower box boundaries denote the 75th and 25th percentiles, respectively, with the median shown as a line within the box. Whiskers indicate minimum and maximum values. Outlying values are denoted as circles
$17 \%$ vs. $4 \%$ ) [21-24]. It should be noted that the sunitinib GIST and RCC trials used a different dosing schedule (sunitinib $50 \mathrm{mg} /$ day, for 4 weeks on therapy, followed by 2 weeks off) than our study and the phase III, pancreatic NET trial.

It is not clear why rates of grade $3 / 4$ hematologic AEs appear to be higher in Japanese versus Western patients who receive sunitinib. Analysis of $\mathrm{PK}$ parameters has shown that the area under the concentration-time values of sunitinib and SU12662 are similar in Japanese and Caucasian patients with RCC [22]. In addition, when steady-state $\mathrm{C}_{\text {trough }}$ values from this Japanese study were compared with those from a Western pancreatic NET population [17] and with $\mathrm{C}_{\text {trough }}$ values from Japanese patients with GIST or RCC [21, 22], there were no significant differences in the dose-corrected $\mathrm{C}_{\text {trough }}$ levels of sunitinib, SU12662, or total drug between Japanese and primarily Western patients with pancreatic NET, or among patients with pancreatic NET, GIST, or RCC. In the absence of racial or ethnic differences in the PK of sunitinib, Uemura et al. [25] suggested that the elevated rates of grade 3/4 hematologic AEs in Japanese patients may be due to differences in the expression levels and activity of sunitinib-sensitive kinases involved in the regulation of hematopoiesis.

Everolimus, an inhibitor of the mammalian target of rapamycin, is approved for the treatment of pancreatic NET in Japan, and like sunitinib is commonly associated with skin and gastrointestinal disorders [9]. Additional AEs related to sunitinib treatment include hematotoxicity, cardiovascular disorders and constitutional symptoms [26], while pneumonitis and infections are associated with everolimus therapy [27]. These different safety profiles reflect each compound's distinct mode of action. No racial differences between Japanese and Western patients have been reported for the safety profile of either drug, based on the current study and a subgroup analysis of Japanese patients in the RADIANT-3 everolimus trial [9].

Treatment-emergent changes in $\mathrm{CgA}$ levels may provide a means to select patients with pancreatic NET likely to benefit from molecular targeted therapy [28]. However, in this study tumor responses in all 12 patients did not appear to correlate with the maximum percentage decrease in $\mathrm{CgA}$ levels, possibly because of small patient numbers with elevated $\mathrm{CgA}$ concentrations at baseline. Patient $\mathrm{D}$ had the highest baseline $\mathrm{CgA}$ levels in the study $(86 \mathrm{pmol} / \mathrm{mL})$, and decreased $\mathrm{CgA}$ concentrations $(-89 \%)$ were subsequently observed in combination with a PR. An increase in CgA levels (300 \%) occurred during the study in 1 patient (Patient L) who experienced PD. A potential correlation between changes in $\mathrm{CgA}$ levels and clinical benefit was considered in these 2 patients. In patients with elevated baseline $\mathrm{CgA}$ concentrations, $\mathrm{CgA}$ appeared to be a useful marker in patients with pancreatic NET as reported previously [29].

The use of sunitinib marks a new phase in the development of a more targeted approach to the treatment of advanced-stage pancreatic NET. Results from the current study demonstrate antitumor activity in Japanese patients with unresectable, well-differentiated pancreatic NET and corroborate earlier findings in Western and Asian populations. 
Acknowledgments We would like to thank all of the participating patients and their families, as well as the network of investigators, research nurses, study coordinators, and operations staff. We are also grateful to Kyoko Okano and Junichi Tanuma (Pfizer Japan Inc.) for their contributions to study management and to Atsushi Shibata for advice regarding the safety profile of sunitinib. Medical writing support was provided by Molly Heitz at ACUMED ${ }^{\circledR}$ (Tytherington, UK) with funding from Pfizer Inc.

Funding This study was sponsored by Pfizer Inc.

Conflict of interest Richard Chao, Satoshi Hashigaki, Nobuyuki Kimura, and Emiko Ohki are employees of Pfizer, and N. Kimura, E. Ohki, and R. Chao hold Pfizer stock. Mami Murakami was previously employed by Pfizer. Tetsuhide Ito, Takuji Okusaka and Kenji Yamao have received research funding from Pfizer. Toshirou Nishida has received research funding from Pfizer and Novartis Pharmaceuticals. Hisato Igarashi, Nobumasa Mizuno, Kazuo Hara, Chigusa Morizane, Shunsuke Kondo, Akira Sawaki, and Masayuki Imamura have no potential conflicts of interest to disclose.

Open Access This article is distributed under the terms of the Creative Commons Attribution License which permits any use, distribution, and reproduction in any medium, provided the original author(s) and the source are credited.

\section{References}

1. Ito T, Sasano H, Tanaka M, Osamura RY, Sasaki I, Kimura W, Takano K, Obara T, Ishibashi M, Nakao K, Doi R, Shimatsu A, Nishida T, Komoto I, Hirata Y, Nakamura K, Igarashi H, Jensen RT, Wiedenmann B, Imamura M (2010) Epidemiological study of gastroenteropancreatic neuroendocrine tumors in Japan. J Gastroenterol 45:234-243

2. Yao JC, Hassan M, Phan A, Dagohoy C, Leary C, Mares JE, Abdalla EK, Fleming JB, Vauthey JN, Rashid A, Evans DB (2008) One hundred years after "carcinoid": epidemiology of and prognostic factors for neuroendocrine tumors in 35,825 cases in the United States. J Clin Oncol 26:3063-3072

3. National Comprehensive Cancer Network (NCCN) (2012) National Comprehensive Cancer Network Clinical Practice Guidelines in Oncology. Neuroendocr Tumors v1.2012

4. Oberg K, Kvols L, Caplin M, Delle Fave G, de Herder W, Rindi G, Ruszniewski P, Woltering EA, Wiedenmann B (2004) Consensus report on the use of somatostatin analogs for the management of neuroendocrine tumors of the gastroenteropancreatic system. Ann Oncol 15:966-973

5. McCollum AD, Kulke MH, Ryan DP, Clark JW, Shulman LN, Mayer RJ, Bartel S, Fuchs CS (2004) Lack of efficacy of streptozocin and doxorubicin in patients with advanced pancreatic endocrine tumors. Am J Clin Oncol 27:485-488

6. Saltz L, Trochanowski B, Buckley M, Heffernan B, Niedzwiecki D, Tao Y, Kelsen D (1993) Octreotide as an antineoplastic agent in the treatment of functional and nonfunctional neuroendocrine tumors. Cancer 72:244-248

7. Raymond E, Dahan L, Raoul J-L, Bang Y-J, Borbath I, LombardBohas C, Valle J, Metrakos P, Smith D, Vinik A, Chen J-S, Hörsch D, Hammel P, Wiedenmann B, Van Cutsem E, Patyna S, Lu DR, Blanckmeister C, Chao R, Ruszniewski P (2011) Sunitinib malate for the treatment of pancreatic neuroendocrine tumors. N Engl J Med 364:501-513

8. Yao JC, Shah MH, Ito T, Bohas CL, Wolin EM, Van CE, Hobday TJ, Okusaka T, Capdevila J, de Vries EG, Tomassetti P, Pavel ME, Hoosen S, Haas T, Lincy J, Lebwohl D, Oberg K (2011)
Everolimus for advanced pancreatic neuroendocrine tumors. N Engl J Med 364:514-523

9. Ito T, Okusaka T, Ikeda M, Igarashi H, Morizane C, Nakachi K, Tajima T, Kasuga A, Fujita Y, Furuse J (2012) Everolimus for advanced pancreatic neuroendocrine tumours: a subgroup analysis evaluating Japanese patients in the RADIANT-3 trial. Jpn J Clin Oncol 42:903-911

10. Casanovas O, Hicklin DJ, Bergers G, Hanahan D (2005) Drug resistance by evasion of antiangiogenic targeting of VEGF signaling in late-stage pancreatic islet tumors. Cancer Cell 8:299-309

11. Inoue M, Hager JH, Ferrara N, Gerber HP, Hanahan D (2002) VEGF-A has a critical, nonredundant role in angiogenic switching and pancreatic beta cell carcinogenesis. Cancer Cell 1:193-202

12. Abrams TJ, Lee LB, Murray LJ, Pryer NK, Cherrington JM (2003) SU11248 inhibits KIT and platelet-derived growth factor receptor beta in preclinical models of human small cell lung cancer. Mol Cancer Ther 2:471-478

13. Mendel DB, Laird AD, Xin X, Louie SG, Christensen JG, Li G, Schreck RE, Abrams TJ, Ngai TJ, Lee LB, Murray LJ, Carver J, Chan E, Moss KG, Haznedar JO, Sukbuntherng J, Blake RA, Sun L, Tang C, Miller T, Shirazian S, McMahon G, Cherrington JM (2003) In vivo antitumor activity of SU11248, a novel tyrosine kinase inhibitor targeting vascular endothelial growth factor and platelet-derived growth factor receptors: determination of a pharmacokinetic/pharmacodynamic relationship. Clin Cancer Res 9:327-337

14. Murray LJ, Abrams TJ, Long KR, Ngai TJ, Olson LM, Hong W, Keast PK, Brassard JA, O'Farrell AM, Cherrington JM, Pryer NK (2003) SU11248 inhibits tumor growth and CSF-1R-dependent osteolysis in an experimental breast cancer bone metastasis model. Clin Exp Metastasis 20:757-766

15. Pietras K, Hanahan D (2005) A multitargeted, metronomic, and maximum-tolerated dose "chemo-switch" regimen is antiangiogenic, producing objective responses and survival benefit in a mouse model of cancer. J Clin Oncol 23:939-952

16. Yao VJ, Sennino B, Davis RB, Christensen JG, Hu-Lowe D, Roberts G, McDonald DM (2006) Combined anti-VEGFR and anti-PDGFR actions of sunitinib on blood vessels in preclinical tumor models. Presented at the 18th EORTC-NCI-AACR symposium, Prague, Czech Republic (Abstract 78)

17. Kulke M, Lenz HJ, Meropol N, Posey J, Ryan DP, Picus J, Bergsland E, Stuart K, Tye L, Huang X, Li J, Baum C, Fuchs C (2008) Activity of sunitinib in patients with advanced neuroendocrine tumors. J Clin Oncol 26:3403-3410

18. Vinik A, Van Cutsem E, Niccoli P, Raoul J-L, Bang Y-J, Borbath I, Valle JW, Metrakos P, Smith D, Chen J-S, Hoersch D, Castellano DE, Kennecke HF, Picus J, Van Hazel G, Patyna S, Lu D, Chao RC, Raymond E (2012) Updated results from a phase III trial of sunitinib versus placebo in patients with progressive, unresectable, well-differentiated pancreatic neuroendocrine tumor (NET). J Clin Oncol 30(suppl abstr 4118)

19. Bosman FT, Carnerio F, Hruban RH et al (2010) WHO classification of tumors of the digestive system (world health classification of tumors). IARC Press, Lyon

20. Therasse P, Arbuck SG, Eisenhauer EA, Wanders J, Kaplan RS, Rubinstein L, Verweij J, Van Glabbeke M, van Oosterom AT, Christian MC, Gwyther SG (2000) New guidelines to evaluate the response to treatment in solid tumors. J Natl Cancer Inst 92:205-216

21. Shirao K, Nishida T, Doi T, Komatsu Y, Muro K, Li Y, Ueda E, Ohtsu A (2010) Phase I/II study of sunitinib malate in Japanese patients with gastrointestinal stromal tumor after failure of prior treatment with imatinib mesylate. Invest New Drugs 28:866-875

22. Tomita Y, Shinohara N, Yuasa T, Fujimoto H, Niwakawa M, Mugiya S, Miki T, Uemura H, Nonomura N, Takahashi M, Hasegawa Y, Agata N, Houk B, Naito S, Akaza H (2010) Overall survival and updated results from a phase II study of 
sunitinib in Japanese patients with metastatic renal cell carcinoma. Jpn J Clin Oncol 40:1166-1172

23. Demetri GD, van Oosterom AT, Garrett CR, Blackstein ME, Shah MH, Verweij J, McArthur G, Judson IR, Heinrich MC, Morgan JA, Desai J, Fletcher CD, George S, Bello CL, Huang X, Baum CM, Casali PG (2006) Efficacy and safety of sunitinib in patients with advanced gastrointestinal stromal tumour after failure of imatinib: a randomised controlled trial. Lancet 368:1329-1338

24. Motzer RJ, Hutson TE, Tomczak P, Dror Michaelson M, Bukowski RM, Oudard S, Negrier S, Szczylik C, Pili R, Bjarnason GA, Garcia-del-Muro X, Sosman JA, Solska E, Wilding G, Thompson JA, Kim ST, Chen I, Huang X, Figlin RA (2009) Overall survival and updated results for sunitinib versus interferon alfa in first-line treatment of patients with metastatic renal cell carcinoma. J Clin Oncol 27:3584-3590

25. Uemura H, Shinohara N, Yuasa T, Tomita Y, Fujimoto H, Niwakawa M, Mugiya S, Miki T, Nonomura N, Takahashi M, Hasegawa Y, Agata N, Houk B, Naito S, Akaza H (2010) A phase
II study of sunitinib in Japanese patients with metastatic renal cell carcinoma: insights into the treatment, efficacy and safety. Jpn J Clin Oncol 40:194-202

26. SUTENT ${ }^{\circledR}$ (sunitinib malate) prescribing information (2012) Pfizer Inc. New York, NY, USA

27. Afinitor ${ }^{\circledR}$ (everolimus) prescribing information (2012) Novartis Pharmaceuticals Corporation, East Hanover, NJ, USA

28. Yao JC, Lombard-Bohas C, Baudin E, Kvols LK, Rougier P, Ruszniewski P, Hoosen S, St PJ, Haas T, Lebwohl D, Van CE, Kulke MH, Hobday TJ, O'Dorisio TM, Shah MH, Cadiot G, Luppi G, Posey JA, Wiedenmann B (2010) Daily oral everolimus activity in patients with metastatic pancreatic neuroendocrine tumors after failure of cytotoxic chemotherapy: a phase II trial. J Clin Oncol 28:69-76

29. Modlin IM, Gustafsson BI, Moss SF, Pavel M, Tsolakis AV, Kidd M (2010) Chromogranin A-biological function and clinical utility in neuro endocrine tumor disease. Ann Surg Oncol $17: 2427-2443$ 